\title{
IceSat-2 Uydu Verilerinden Elde Edilen Nokta Bulutu Verilerinden Kar Kalınlığı Belirleme Potansiyelinin Analizi
}

\author{
${ }^{* 1}$ Büşra Şahin, ${ }^{1}$ Sinem Çetinkaya, ${ }^{2}$ A. Kürşat Özcan, ${ }^{1}$ Ali Özgün Ok, ${ }^{1}$ Sultan Kocaman, ${ }^{3}$ Candan Gökçeoğlu \\ ${ }^{1}$ Hacettepe Üniversitesi, Geomatik Mühendisliği Bölümü, Ankara, Türkiye \\ (busrasahin13, sinemcetinkaya, ozgunok, sultankocaman@ hacettepe.edu.tr) \\ ${ }^{2}$ Çölleşme ve Erozyonla Mücadele Genel Müdürlüğü, Tarım ve Orman Bakanlığı, Ankara, Türkiye \\ (ademkursat@gmail.com) \\ ${ }^{3}$ Hacettepe Üniversitesi, Jeoloji Mühendisliği Bölümü, Ankara, Türkiye \\ (cgokce@hacettepe.edu.tr)
}

\section{Özet:}

Önemli doğal tehlikelerden biri olan çı̆̆, bitki örtüsünün seyrek olduğu veya bulunmadığı, kar yağışının fazla olduğu dağlık bölgelerde iç veya dış kuvvetlerin etkisiyle kar kütlesinin eğim yönünde hareketiyle gerçekleşmektedir. Çığ düşmesi sonucunda ise yerleşim alanları, ekonomik faaliyetler ve ulaşım etkilenebilmekte, ayrıca can ve mal kaybı yaşanabilmektedir. Türkiye'nin özellikle kuzey ve doğu bölgelerinde, jeomorfolojik ve iklimsel özellikleri sebebiyle çı̆̆ düşmesine oldukça yatkın dağlık alanlar bulunmaktadır. Örneğin 2020 yılının başlarında Van ilinin Başkale ilçesinde arka arkaya çığ afeti yaşanmıştır. Son yıllarda yapılan çalışmalarda çı̆̆ tehlikesi tahmini için ilk adım olan kar kalınlığının belirlenmesinde aktif ve pasif sensörlerden yararlanılmıştır. Yapılacak tahminlerle çı̆̆ tehlikesine karşı önlemler alınması sağlanarak, neden olduğu zararları en aza indirmek veya ortadan kaldırmak mümkün olabilir. IceSat-2 (The Ice, Cloud and Land Elevation Satellite - 2) buzul ve buz tabakalarındaki kütle ve yükseklik değiş̧ikliğinin ölçülmesi, eriyen buz kütlelerin deniz seviyesindeki değişikliğe etkisinin araştırılmasına olanak sağlayan yeni bir uydu platformudur. IceSat-2 uydusunda ATLAS (Advanced Topographic Laser Altimeter System) LiDAR (Light Detection and Ranging) algılayıcı sistemi kullanılmışıır. Bu çalışmada, IceSat-2 platformu ATLAS algılayıcısından elde edilen nokta bulutu verilerinin doğruluk analizi gerçekleştirilmiştir. Bu kapsamda Erzurum ve Van Ferit Melen Havalimanları hem kar kalınlığı bilgisine sahip olması hem de doğruluk karşılaştırması için düz yüzeyler sağlaması açısından çalışma alanı olarak belirlenmiştir. IceSat-2 uydusundan elde edilen veriler güvenilirlik düzeylerine göre filtrelenerek çalışma alanlarına ait yüksek çözünürlüklü sayısal yükseklik modelleri ile LiDAR noktalarının gerçek arazi yükseklikleri ile arasındaki farklar karşılaştırmalı olarak incelenmiş olup IceSat-2 verilerinden kar kalınlığı belirlenme potansiyeli tartı̧̧ılmıştır.

Anahtar Kelimeler: Afet, Çı̆̆, Icesat-2, LiDAR, Doğruluk

\section{Abstract: \\ Analysis of Snow Depth Determination Potential from Point Cloud Data Obtained from IceSat-2 Satellite Data}

Avalanche, as one of the important natural hazards, occurs in mountainous regions where the vegetation canopy is sparse or does not exist, snowfall is high, and the snow mass moves in the

\footnotetext{
* Sorumlu Yazar: Büşra Şahin Adres: Hacettepe Üniversitesi, Geomatik Mühendisliği Bölümü, 06800, Ankara, TÜRKIYE. E-mail adres: busrasahin13@ @acettepe.edu.tr
} 


\begin{abstract}
direction of the slope with the effect of internal or external forces. As a result of avalanches, residential areas, economic activities, and transportation may be affected, and loss of life and property may occur. There are quite prone regions in Turkey, especially in the northern and eastern regions, to avalanches in mountainous areas due to geomorphological and climatic characteristics. For instance, at the beginning of year 2020, avalanche disasters occurred one after the other in the Başkale district of Van province. In recent studies, active and passive sensors have been used to determine the snow depth, which is the first step for the prediction of avalanche hazard. It may be feasible to minimize or eliminate the damages caused by taking precautions against avalanche danger with predictions. IceSat2 (The Ice, Cloud and Land Elevation Satellite - 2) is a new satellite platform that allows the measurement of mass and altitude change in glaciers and ice sheets, and the effect of melting ice masses on sea-level change. ATLAS (Advanced Topographic Laser Altimeter System) LiDAR (Light Detection and Ranging) sensor system used on the IceSat-2 satellite. In this study, the accuracy analysis of the point cloud data obtained from the IceSat-2 platform of the ATLAS sensor was performed. In this context, Erzurum and Van Ferit Melen Airports were determined as the study area due to both having snow depth information and allowing flat surfaces for accuracy comparison. The differences between the high-resolution digital elevation models of the study areas and the terrain heights of the LiDAR points were comparatively analyzed by filtering the data obtained from the IceSat-2 satellite according to their confidence levels, and the potential of determining snow depth from IceSat-2 data was discussed.
\end{abstract}

Key Words: Disaster, Avalanche, Icesat-2, LiDAR, Accuracy

\title{
1. Giriş
}

Kar, yüksek albedoya, düşük 1sıl iletkenliğe sahip olduğundan küresel radyasyon dengesini yöneterek, Dünya'nın atmosferik dönüşümünü ve iklim özelliklerini etkileyen temel tetikleyici güçtür [1]. Soğuk iklimlerin hakimiyet sürdüğü bölgelerde kar, hidroelektrik santrallerin üretimlerine katkısı ve kış rekreasyon alanlarındaki rolüyle toplumda önemli bir yere sahip olsa da, aynı zamanda taşkın ve çı̆̆ riskine neden olmaktadır [2]. Dik dağlık arazilerdeki dinamik ve değişken kar örtüsünün doğal bir sonucu olan çığ, az rastlanan doğa olaylarından biri olmasına rağmen can ve mal kaybına, alt yapı sorunlarına sebep olmakta, ekonomik faaliyetleri ve ulaşımı etkilemektedir. Çığ tahmini çalışmalarında istikrarsızlığın en aza indirilmesi için: (i) kar örtüsünün zamansal ve mekânsal değişkenliği; (ii) kar ve hava koşullarının değiş̧kenliği; (iii) insan algısından kaynaklı değişkenler göz önünde bulundurmalıdır [3]. Doğrudan kar kalınlığı ölçümlerinin dağlık, engebeli, yüksek ve uzak olmasından dolayı, kar kalınlığının belirlenmesinde uzaktan algılama tekniklerinin kullanımı gittikçe artmıştır. Yer gözlem uydularının küresel kapsamda veri toplayabilmeleri, ölçülerin düzenli aralıklarla tekrarlanabilirliği, çok sayıda sensör ve sensör platformlarının mevcut olması, zamansal ve mekânsal yüksek değişken kar örtüsünün kapsamlı ve güvenli bir şekilde izlenmesine olanak tanıyabilmektedir [4]. Kar olan ve kar olmayan zamanlara ait Sayısal Yüzey Modelleri (SYM) ile yamaç, bakı ve yüksekliğe bağlı analizler yapılmakta, kar kalınlığının belirlenmesinde ise genellikle yükseklik farkından yararlanılmaktadır [5][6].

15 Eylül 2018 tarihinde NASA tarafindan firlatılan IceSat-2 uydusunun (The Ice, Cloud and land Elevation Satellite - 2) öncelikli görevi kriyosferdeki değişikliklerin izlenerek buzul ve buz tabakalarındaki kütle, yükseklik değişikliğinin ölçülmesi ve eriyen buz kütlelerin deniz seviyesindeki değişimine etkisinin araştırılmasıdır. Diğer taraftan IceSat-2, Dünya'nın karasal yüzeyleri hakkında bilgi toplayarak, ormanlar ve diğer ekosistemlerdeki bitki örtüsü ve Dünya 
yüzeyinde küresel yükseklik verisi elde edilmesine olanak sağlayarak çeşitli uygulamalara dönük jeodezik ölçümler sağlamaktadır [7]. Uyduda yenilikçi ve yüksek kapasiteli ATLAS (Advanced Topographic Laser Altimeter System) lazer altimetre algılayıcı sistemi kullanılmıştır. Neuenschwander ve Magruder [8], farklı konum, arazi ve ekosistem çeşitliliği elde edilen sonuçların IceSat-2 performansını zamanla daha da artırılabileceğini ifade etmiştir.

Bu çalışmada günlük olarak kar kalınlığı ölçümleri yapılan meteoroloji istasyonlarının bulunduğu Erzurum ve Van Ferit Melen Havalimanları test alanları olarak tercih edilmiştir. Pistlerin yer aldığ 1 görece düz yüzeyler yerleşim alanı ve bitki örtüsü içermemesi nedeniyle hassasiyet analizi açısından uygun bulunmuştur. Seçilen test alanlarında mevsimsel sıcaklık farklarının yüksek olduğu kış aylarına (Ekim-Mart) ait ATL08 üç-boyutlu (3B) uydu LiDAR nokta verileri seviye 3A ürünü olarak temin edilmiştir. MatLab ortamında bu veriler belirli güvenilirlik düzey değerlerine göre ayrılmış ve doğruluk analizleri gerçekleştirilmiştir. Referans veri olarak hâlihazır haritalardan üretilmiş $10 \mathrm{~cm}$ çözünürlüklü SYM kullanılmıştır. ATL08 verileri ve referans SYM'ler arasındaki farklar dikkate alınarak verilerin düşey konum doğruluğu analiz edilmiştir. Çalışmanın ilerleyen aşamalarında, ATL08 verileri kullanılarak olası kar kalınlığı belirleme potansiyelinin ortaya çıkarılması hedeflenmiştir.

\section{2. Çalışma Alanı}

Türkiye'de çığ olaylarının sıkça rastlandığı Doğu Anadolu Bölgesi içerisinde yer alan Erzurum ve Van Ferit Melen Havalimanları kar kalınlık verilerine ve uydu LiDAR nokta bulutu verilerine ulaşılabilirliği açısından çalışma alanı olarak seçilmiştir. Erzurum Havalimanı ve Van Ferit Melen Havalimanı merkez noktaları sirasiyla $39^{\circ} 57^{\prime} 10.4^{\prime \prime} \mathrm{K}, 41^{\circ} 11^{\prime} 22.9^{\prime \prime} \mathrm{D}$ ve $38^{\circ} 28^{\prime} 08.4^{\prime \prime} \mathrm{K}$, $43^{\circ} 20^{\prime} 13.2^{\prime \prime} \mathrm{D}$ yükseklik değerleri ortalama deniz seviyesinden yine sırasıyla 1751.60-1757.10 m ve 1649.03-1670.10 m aralığında olup, uydu veri alımı Kuzey-Güney yönündedir.

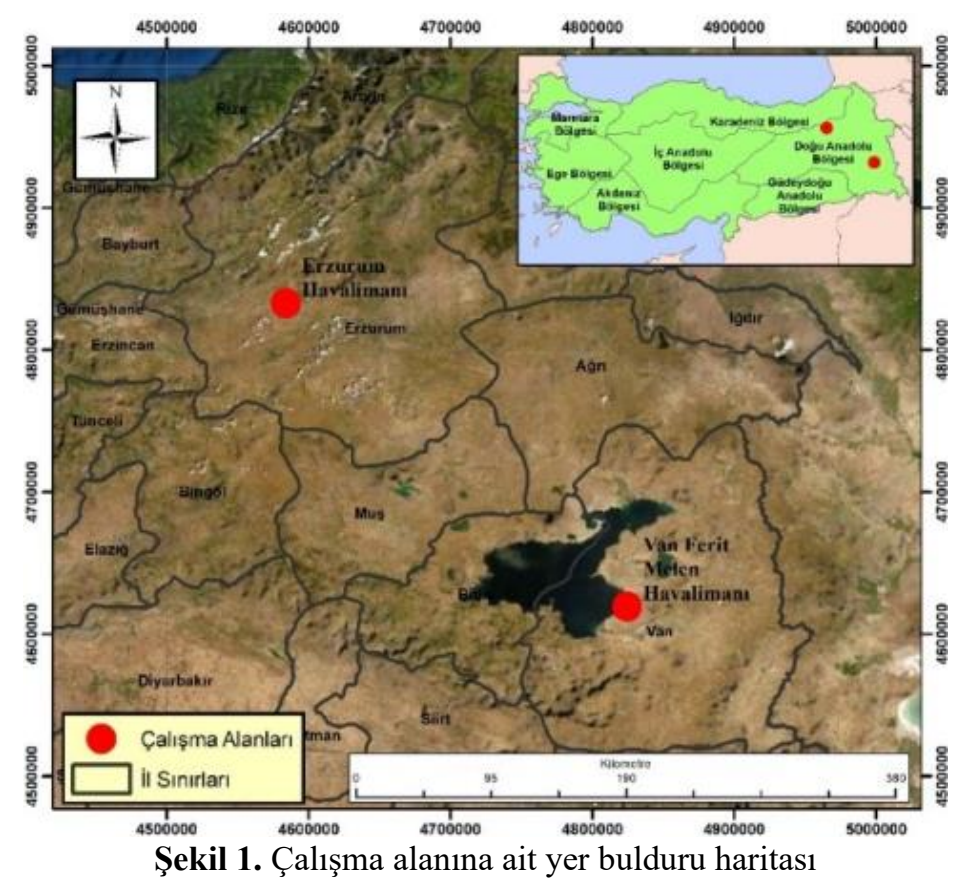


Meteoroloji Genel Müdürlüğü (MGM) tarafından 1929-2019 yılları arasında test alanlarının bulunduğu illere ait uç değerler göz önünde bulundurulduğunda; Erzurum ili için ölçülen sıcaklık değerleri $36.5^{\circ} \mathrm{C}-37.2^{\circ} \mathrm{C}$ aralığında, günlük en hızlı rüzgar $110.2 \mathrm{~km} / \mathrm{sa}$, en yüksek kar $110.0 \mathrm{~cm}$ kalınlığındadır [9]. Van ili için ölçülen sıcaklık değerleri $37.5^{\circ} \mathrm{C}-28,7^{\circ} \mathrm{C}$ aralığında, günlük en hızlı rüzgâr $165.6 \mathrm{~km} / \mathrm{sa}$, en yüksek kar $120.0 \mathrm{~cm}$ kalınlığındadır. Yaz ve kış aylarında sıcaklık farkının yüksek olduğu çalışma alanlarında, şiddetli karasal iklim hâkim olmaktadır. Çalışma alanı, en yaşı birimi Erzurum Kars Ofiyolit Zonu olan Doğu Anadolu Yığışım Karmaşı̆̆ı'nın içerisinde, Pontid ve Anatolid tektonik bölgeleri arasında kalmaktadır. Balkanlar'dan başlayarak, Türkiye'nin doğusundan İran'a kadar uzanan Kuroko tipi masif sülfid yataklarının ve porfiri Cuyataklarının da yer aldığı kuşaktadır.

\section{Veri ve Yöntemler}

Bu bölümde çalışmada kullanılan IceSat-2 uydusuna ait bilgilere, elde edilen verilere yönelik açıklamalara ve kullanılan verilerin işlenmesi yönelik detaylara yer verilmektedir.

\subsection{Sensör Özellikleri}

IceSat-2 uydu misyonunda eriyen buz tabakalarının ölçümü ve eriyen buz tabakalarının deniz seviyesindeki yükselmeye etkisi, buzul kütlelerdeki değişiklikler, deniz buzul kalınlığının tahmin edilmesi ve araştırılması temel hedeftir. IceSat-2 uydu yörüngesine ait bazı temel teknik özellikler Tablo 1'de görülmektedir. IceSat-2 uydusunda gelişmiş foton sayma teknolojisine göre tasarlanmış ATLAS sensörü verileri ile üç seviyede toplam 21 tip veri ürünü üretilir. Yeniden Formatlanmış Telemetri (ATL01) ve Bilimsel Birime Dönüştürülmüş Telemetri (ATL02) Seviye1 ürünleridir. Fotonların coğrafi konumu (ATL03), kalibre edilmemiş geri yansıma profili (ATL04) verileri Seviye-2 ürünlerindendir. Kara buzu yüksekliği (ATL06), deniz buzu yüksekliği (ATL07), kara ve bitki örtüsü yüksekliği (ATL08) gibi veriler Seviye-3A'nın ürünleridir. Seviye3B, haftalık (ATL16) ve aylık (ATL17) atmosfer verileri, 1zgaralı (grid) kara ve bitki örtüsü yüksekliği (ATL18), ve ortalama deniz yüzeyi yüksekliği (ATL19) gibi verileri içermektedir [10].

Tablo 1. IceSat-2 uydusu yörünge teknik özellikleri

\begin{tabular}{|l|l|}
\hline \multicolumn{2}{|c|}{ Yörünge Özellikleri } \\
\hline İnklinasyon açısı & $92^{\circ}$ \\
\hline Platform Yüksekliği & $\sim 500 \mathrm{~km}$ \\
\hline Yarı büyük eksen & $6855 \mathrm{~km}$ \\
\hline Zamansal çözünürlük & 91 gün \\
\hline
\end{tabular}

ATLAS, yeryüzünden $500 \mathrm{~km}$ yükseklikteki yörüngede $532 \mathrm{~nm}$ yeşil dalga boyu kullanarak 2x3'lük bir dizi olarak tasarlanmış 3 çift ışını tek atımda gönderir. Işın çifti yeryüzündeki farklı yansımaları karşılamak için zayıf ve güçlü iletim enerjilerine (1:4 enerji oranıyla) sahiptir. Işın çiftleri uydunun izlediği hatta dik $\sim 3.3 \mathrm{~km}$, zayıf ve güçlü 1 şınlar hat boyunca $\sim 2.5 \mathrm{~km}$ ayrı saçılarak veri alırlar. Her ş̧ın yaklaşık $17 \mathrm{~m}$ çapında bir ayak izine sahip olup her iki ayak izi arasındaki mesafe $70 \mathrm{~cm}$ olacak şekilde tasarlanmıştır. Lazer darbeleri uçuş süresine (time-offlight) göre kaydedilir (Tablo 2). Alıcı sistem, tek foton duyarlı detektörlerle geri dönen lazer 1şının varış süresini kaydeder. Hassas olarak belirlenmiş foton gidiş-varış (uçuş) süreleri ATL02 
veri ürünleriyle birlikte yayımlanmaktadır. ATL03, ATL02 ürünündeki her fotonun WGS 84 elipsoidine göre coğrafi konumunu hesaplanmış veri ürünüdür [10]-[13]. ATL03 coğrafi konum çözümlerinin kalitesi, uçak ve yer ölçümlerinden bağımsız ölçümlerle karşılaştırılarak doğrulanır [11]. Üretilen verilerde yükseklik doğruluğunu etkileyen çeşitli parametreler vardır. Yükseklik doğruluğu; radyal yörünge belirsizliği, coğrafi konum bilgisi, atmosferik saçılmalar ve troposfer kaynaklı yol gecikme hataları gibi parametrelerden etkilenmektedir. Radyal yörünge belirsizliği en fazla $4 \mathrm{~cm}$ ve troposfer kaynaklı yol gecikme hatası yaklaşık olarak $3 \mathrm{~cm}$ olarak tahmin edilmektedir. Bütün hata kaynakları göze alındığında düz yüzeyler için hassasiyetin yaklaşık 25 cm standart sapmaya sahip olması beklenmektedir [13].

Tablo2. ATLAS sensörünün temel özellikleri

\begin{tabular}{|l|l|}
\hline \multicolumn{2}{|c|}{ ATLAS Sensörünün Temel Özellikleri } \\
\hline Darbe tekrarlama frekansı (kHz) & 10 \\
\hline Ölçüm yaklaşımı & Foton sayma \\
\hline Dalga boyu (nanometre) & $532.272 \pm 0.15$ \\
\hline Ayak izi çapı (m; mikroradyan) & $<17.4$ \\
\hline Darbe genişliği (nanosaniye) & $<1.5$ \\
\hline Darbe enerjisi (milijoules) & $0,2-1,2$ \\
\hline Işın sayısı & 6 \\
\hline Işın enerjisi oranı (güçlü: zayıf) & $4: 1$ \\
\hline Darbe başına ışın enerjisi (güçlü, zayıf) (microjoules) & $175 \pm 17,45 \pm 5$ \\
\hline
\end{tabular}

\subsection{Veriler}

IceSat-2 uydu misyonu 14 Ekim 2018 tarihinden beri veri sağlamaktadır. Çalışmada kullanılan tüm veriler ücretsiz veri sağlayan OpenAltimetry platformundan temin edilmiştir. OpenAltimetry, NSIDC (National Snow and Ice Data Center) ile iş birliği içinde çalışan NASA'nın IceSat ve IceSat-2 uydu misyonlarından gelen verilerin erişimi ve görselleştirilmesini sağlayan ortak bir platformdur. Sunulan ürünlerden ATL08: ATLAS/IceSat-2 Seviye 3A (L3A) Arazi ve Bitki Örtüsü Yüksekliği (Land and Vegetation Height) verileri kullanılmıştır. ATL08 ölçüm yaptığı hat boyunca arazi yüksekliği, bitki (canopy) yüksekliği ve bitki örtüsü ile ilgili tahminler ve çalışmalar yapılmasını sağlamaktadır. Ayrıca ülkemizde bulunan 954 meteoroloji istasyon koordinatları, aylık ve günlük kar kalınlığı verileri ile ilgili veri tabanı Çölleşme ve Erozyonla Mücadele Genel Müdürlüğü tarafından sağlanmıştır. Ayrıca, test alanlarına ait hâlihazır haritalardan üretilmiş $10 \mathrm{~cm}$ çözünürlüklü SYM referans olarak kullanılmıştır.

\subsection{Veri İşleme Stratejisi}

Burada IceSat-2 platformu ATLAS sensöründen elde edilen nokta bulutu verilerinin doğruluk analizleri gerçekleştirilmiştir. Uydu yörüngesi küresel konumlama sistemleri vasıtasıyla WGS-84 elipsoidi üzerinde hassas olarak ölçülmektedir. Uydudan elde edilen nokta bulutu yükseklikleri de WGS-84 elipsoidine göre hesaplanmaktadır. Ancak bu çalışmada doğrulama amacıyla kullanılan referans SYM ortometriktir ve jeoid üzerinde tanımlanmıştır. Datum farkının giderilerek elipsoid-ortometrik yükseklik dönüşümünün gerçekleştirilebilmesi için, test alanlarında jeoid ondülasyonu $(\mathrm{N})$ bilgisi kullanılmıştır. Bu amaçla, Harita Genel Müdürlüğü 
(HGM) tarafından Türkiye Yükseklik Sisteminin Modernizasyonu ve Gravite Altyapısının İyileştirilmesi Projesi kapsamında hesaplanan Türkiye Jeoidi - 2019 (TG-19) [14] verisinden elde edilen en güncel jeoid ondülasyon değerlerinden yararlanılarak her havalimanı için sabit bir $\mathrm{N}$ değeri LiDAR noktalarının yükseklik dönüşümünde kullanılmıştır.

Erzurum ve Van Ferit Melen havalimanları pistleri çevresinde kış aylarına ait ATLAS LiDAR nokta bulutunun ayak izleri Şekil 2'te verilmiştir. Uydunun 3 Ekim 2019 tarihli geçişinde 3 çift 1şından ikisi Erzurum havalimanından ölçüm almıştır. Bu nedenle pistlerin üzerinden alınan veri 3 Ekim 2019_1, pistin yakınından alınan veri ise 3 Ekim 2019 2 olarak adlandırılmıştır. Doğruluk analizleri sırasında öncelikle LiDAR verisi içinde bulunan güvenilirlik düzeyi (confidence level) değerleri dikkate alınmıştır. Her bir LiDAR noktasının güvenilirlik düzeyi 0-4 arasında hâlihazırda sınıflandırılmış olup; 0-gürültü, 1-olası foton sinyali, 2-düşük güvenilirlik, 3orta güvenilirlik ve 4-yüksek güvenilirlik düzeyini belirtmektedir [13]. Bu çalışmadaki doğruluk analizleri için LiDAR verisinden (i) sadece yüksek (4) noktalar ve (ii) orta ve yüksek noktalar beraber (3-4) olacak şekilde fotonlar filtrelenmiştir. Referans SYM dişında kalan noktalar analizlerden çıkarılmıştır. Kullanılan noktalar için güvenilirlik düzeyleri dikkate alınarak (sadece yüksek ve orta ve yüksek beraber) yükseklik istatistikleri (Tablo 3 ve Tablo 4) çıkarılmış ve referans SYM'ler ile karşılaştırılmıştır.
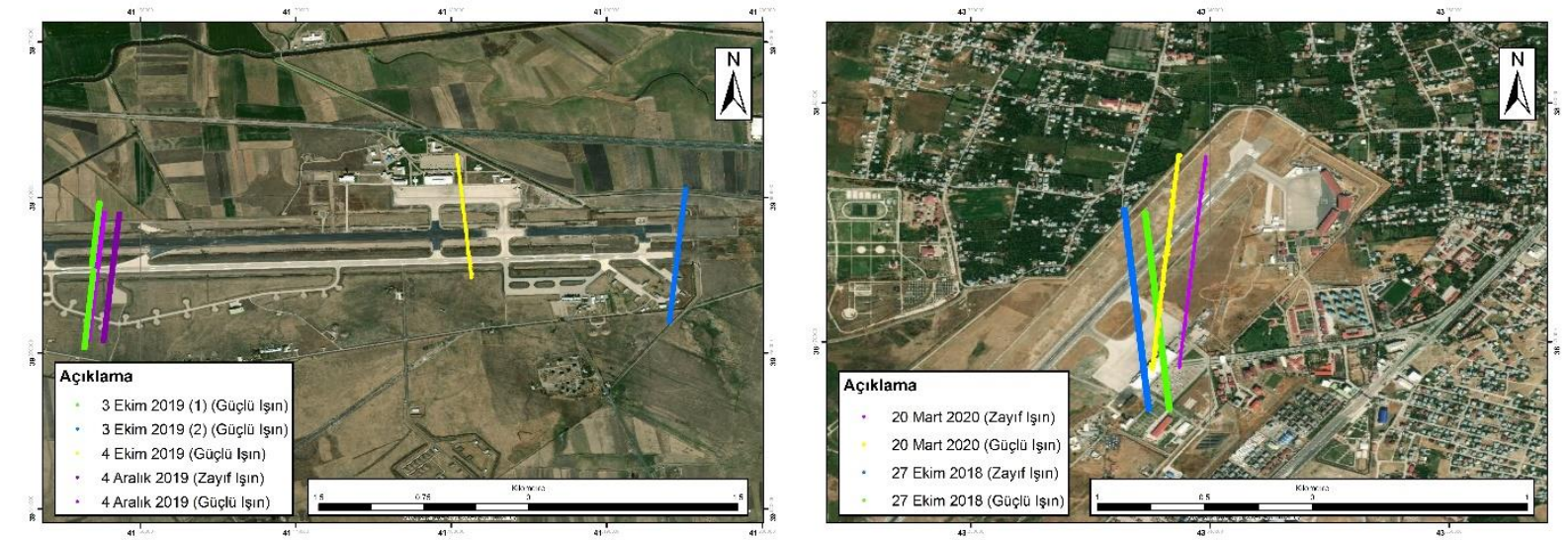

Şekil 2. (sol) Erzurum Havalimanı ve (sağ) Van Ferit Melen Havalimanı IceSat-2 uydusu tarafından toplanan veriler

\section{Bulgular ve Tartışma}

Karşılaştırmalar sırasında elde edilen yükseklik farkları (hata), 8 farklı istatistiksel parametre (minimum, maksimum, ortalama değer, ortanca değer, ortalama mutlak hata, ortanca mutlak hata, standart sapma ve ortalama karesel hata) ile değerlendirilmiştir. İki farklı güvenilirlik düzeyinde elde edilen tüm sonuçlar Tablo 5 ve Tablo 6'da sunulmuştur. Tablo 5 ve Tablo 6'da görüldüğü üzere Erzurum Havalimanında 3 Ekim 2019 tarihinde elde edilen veriler hem pist yakınında hem de pist üzerinde yer almakta olup nokta sayısı bakımından yüksek güvenilirlik düzeyinde görece az sayıda nokta bulunduğu görülmektedir. Aynı tarihli veri için güvenilirlik düzeyleri yüksek olan noktalara orta güvenilirlik düzeye sahip lazer verileri eklendiğinde ise toplam değerlendirilen nokta sayısı iki kattan fazla $(\approx 2.3 \mathrm{x})$ artmış ve bu artış hassasiyet sonuçlarını negatif olarak etkilemiştir (Tablo 6). Bu tarihli veride orta güvenilirlik düzeyindeki verilerde kaba 
Tablo 3. ATL08 nokta bulutu ortometrik yükseklik veri istatistikleri (Güvenilirlik düzeyi yüksek).

\begin{tabular}{|c|c|c|c|c|c|c|}
\hline Test Alanı & Tarih & & Minimum (m) & Maksimum (m) & Ortalama (m) & Medyan (m) \\
\hline \multirow{5}{*}{$\begin{array}{l}\text { Erzurum } \\
\text { Havalimanı }\end{array}$} & 3 Ekim 2019 (1) & güçlü 1şın & 1756.67 & 1757.33 & 1757.10 & 1757.13 \\
\hline & 3 Ekim 2019 (2) & güçlü ışın & 1753.79 & 1756.54 & 1755.39 & 1755.70 \\
\hline & 4 Ekim 2019 & güçlü 1şın & 1752.20 & 1756.86 & 1755.61 & 1755.70 \\
\hline & & güçlü 1şın & 1755.47 & 1756.81 & 1756.07 & 1755.93 \\
\hline & 4 Aralık 2019 & zayıf 1şın & 1753.35 & 1757.38 & 1756.05 & 1756.20 \\
\hline \multirow{4}{*}{$\begin{array}{l}\text { Van Ferit Melen } \\
\text { Havalimanı }\end{array}$} & & güçlü ışın & 1658.61 & 1662.71 & 1661.61 & 1662.04 \\
\hline & 27 Ekim 2018 & zayıf 1şın & 1658.69 & 1661.92 & 1660.73 & 1661.08 \\
\hline & & güçlü 1şın & 1659.15 & 1667.52 & 1662.78 & 1663.18 \\
\hline & 20 Mart 2020 & zayıf 1şın & 1661.88 & 1665.13 & 1664.00 & 1664.53 \\
\hline
\end{tabular}

Tablo 4. ATL08 nokta bulutu ortometrik yükseklik veri istatistikleri (Güvenilirlik düzeyi orta ve yüksek)

\begin{tabular}{|c|c|c|c|c|c|c|}
\hline Test Alanı & Tarih & & Minimum (m) & Maksimum (m) & Ortalama (m) & Medyan (m) \\
\hline \multirow{5}{*}{$\begin{array}{l}\text { Erzurum } \\
\text { Havalimanı }\end{array}$} & 3 Ekim 2019 (1) & güçlü 1şın & 1753.23 & 1757.60 & 1756.43 & 1756.72 \\
\hline & 3 Ekim 2019 (2) & güçlü 1şın & 1752.26 & 1756.69 & 1755.18 & 1755.53 \\
\hline & 4 Ekim 2019 & güçlü ışın & 1752.20 & 1773.62 & 1755.62 & 1755.70 \\
\hline & & güçlü 1şın & 1754.58 & 1757.32 & 1756.30 & 1756.40 \\
\hline & 4 Aralık 2019 & zayıf 1şın & 1753.35 & 1757.38 & 1756.02 & 1756.19 \\
\hline \multirow{4}{*}{$\begin{array}{l}\text { Van Ferit Melen } \\
\text { Havalimanı }\end{array}$} & & güçlü ışın & 1658.61 & 1663.12 & 1661.58 & 1661.99 \\
\hline & 27 Ekim 2018 & zayıf 1şın & 1658.37 & 1662.14 & 1660.77 & 1661.14 \\
\hline & & güçlü 1şın & 1659.15 & 1667.52 & 1662.78 & 1663.18 \\
\hline & 20 Mart 2020 & zayıf 1şın & 1661.88 & 1674.94 & 1664.04 & 1664.53 \\
\hline
\end{tabular}

hatalar bulunduğu Tablo 5 ve Tablo 6'da görülen minimum ve maksimum hata değerlerinden ve hesaplanan standart sapma değerlerinden anlaşılmaktadır.

Bazı verilerde kaba hatalar bulunduğu Tablo 5'te görülen minimum ve maksimum hata değerlerinden anlaşılmaktadır. Ancak güvenilirlik düzeyi yüksek olarak belirtilen veride ortalama karesel hatalar oldukça dar bir bantta değişmektedir $(0.32 \mathrm{~m}-0.49 \mathrm{~m})$. Yüksek güvenilirlik düzeyine sahip verilere orta güvenilirlik düzeyine sahip veriler eklendiğinde ise ortalama karesel hataların belirli oranlarda arttı̆̆ görülmektedir.

Tablo 5'te 4 Aralık 2019 güçlü ışın ve 20 Mart 2020 zayıf ışın verilerinde elde edilen maksimum farkların Tablo 6'da belirgin olarak değişmesi ve ancak ortalama hataların fazla değişmemiş olması, kaba hatalı nokta sayısının veride az sayıda bulunduğunu da ifade etmektedir. Güvenilirlik düzeyinde değişiklik her iki veride de standart sapma ve ortalama karesel hata değerlerinde görece yüksek değişikliklere yol açmıştır. Güçlü ve zayıf ışın olarak toplanan verilerin yüksek güvenilirlik düzeyinde maksimum, minimum değerlerde azalma gözlemlenirken standart sapma, ortalama karesel hata, ortalama ve ortanca hata değerlerinde anlamlı değişiklikler gözlenmemiştir.

Tüm değerlendirmeler sonucunda IceSat-2 verilerinin güvenilirlik düzeyi yüksek verilerinin de kaba hatalar içerebildiği ancak orta güvenilirlik düzeyi verilerinin daha fazla seviyede hatalar barındırdığı ortaya çıkmaktadır. Bu kapsamda hataları azaltmak için sadece güvenilirliği yüksek 
Tablo 5. ATL08 nokta bulutu ile SYM ortometrik yükseklik veri karşılaştırmalı istatistikleri (birim "metre") (Güvenilirlik düzeyi sadece yüksek)

\begin{tabular}{|c|c|c|c|c|c|c|c|c|c|c|c|}
\hline Test Alanı & Tarih & & $\begin{array}{l}\text { Toplam } \\
\text { Nokta } \\
\text { Sayısı }\end{array}$ & Min. & Maks. & Ort. & Med. & $\begin{array}{c}\text { Ort. } \\
\text { Mutlak } \\
\text { Hata }\end{array}$ & $\begin{array}{c}\text { Ortanca } \\
\text { Mutlak } \\
\text { Hata }\end{array}$ & $\begin{array}{c}\text { Standart } \\
\text { Sapma }\end{array}$ & $\begin{array}{c}\text { Ort. } \\
\text { Karesel } \\
\text { Hata }\end{array}$ \\
\hline \multirow{5}{*}{$\begin{array}{l}\text { Erzurum } \\
\text { Havalimanı }\end{array}$} & $\begin{array}{l}3 \text { Ekim } \\
2019(1) \\
\end{array}$ & güçlü ışın & 90 & -0.20 & 0.52 & 0.29 & 0.30 & 0.30 & 0.30 & 0.12 & 0.32 \\
\hline & $\begin{array}{l}3 \text { Ekim } \\
2019(2) \\
\end{array}$ & güçlü ışın & 428 & -0.28 & 1.25 & 0.34 & 0.32 & 0.35 & 0.32 & 0.19 & 0.39 \\
\hline & $\begin{array}{l}\text { 4 Ekim } \\
2019\end{array}$ & güçlü 1şın & 2156 & -3.85 & 1.90 & 0.33 & 0.30 & 0.36 & 0.30 & 0.30 & 0.45 \\
\hline & \multirow{2}{*}{$\begin{array}{l}\text { 4 Aralık } \\
2019\end{array}$} & güçlü ışın & 92 & -0.99 & 1.28 & 0.35 & 0.32 & 0.38 & 0.33 & 0.29 & 0.45 \\
\hline & & zayıf ışın & 1058 & -1.15 & 2.59 & 0.29 & 0.27 & 0.35 & 0.29 & 0.35 & 0.46 \\
\hline \multirow{4}{*}{$\begin{array}{l}\text { Van Ferit } \\
\text { Melen } \\
\text { Havalimanı }\end{array}$} & \multirow{2}{*}{$\begin{array}{l}27 \text { Ekim } \\
2018\end{array}$} & güçlü ışın & 1457 & -1.50 & 0.63 & -0.30 & -0.26 & 0.32 & 0.27 & 0.26 & 0.40 \\
\hline & & zayıf 1şın & 358 & -0.89 & 0.41 & -0.31 & -0.34 & 0.33 & 0.34 & 0.23 & 0.39 \\
\hline & \multirow{2}{*}{$\begin{array}{l}20 \text { Mart } \\
2020\end{array}$} & güçlü işın & 1959 & -4.05 & 2.63 & -0.22 & -0.25 & 0.33 & 0.28 & 0.37 & 0.44 \\
\hline & & zayılf ışın & 322 & -2.66 & 0.06 & -0.39 & -0.36 & 0.40 & 0.36 & 0.29 & 0.49 \\
\hline
\end{tabular}

Tablo 6. ATL08 nokta bulutu ile SYM ortometrik yükseklik veri karşılaştırmalı istatistikleri (birim "metre")

(Güvenilirlik düzeyi orta ve yüksek beraber)

\begin{tabular}{|c|c|c|c|c|c|c|c|c|c|c|c|}
\hline Test Alanı & Tarih & & $\begin{array}{c}\text { Toplam } \\
\text { Nokta } \\
\text { Sayısı } \\
\end{array}$ & Min. & Maks. & Ort. & Med. & $\begin{array}{c}\text { Ort. } \\
\text { Mutlak } \\
\text { Hata }\end{array}$ & $\begin{array}{c}\text { Ortanca } \\
\text { Mutlak } \\
\text { Hata } \\
\end{array}$ & $\begin{array}{c}\text { Standart } \\
\text { Sapma }\end{array}$ & $\begin{array}{c}\text { Ort. } \\
\text { Karesel } \\
\text { Hata }\end{array}$ \\
\hline \multirow{5}{*}{$\begin{array}{l}\text { Erzurum } \\
\text { Havalimanı }\end{array}$} & $\begin{array}{l}3 \text { Ekim } \\
2019(1)\end{array}$ & güçlü 1 şın & 435 & -1.54 & 2.26 & 0.38 & 0.37 & 0.48 & 0.39 & 0.43 & 0.58 \\
\hline & $\begin{array}{l}3 \text { Ekim } \\
2019(2)\end{array}$ & güçlü 1şın & 768 & -2.32 & 1.72 & 0.23 & 0.30 & 0.39 & 0.34 & 0.42 & 0.48 \\
\hline & $\begin{array}{l}\text { 4 Ekim } \\
2019 \\
\end{array}$ & güçlü ışın & 2157 & -3.85 & 18.26 & 0.34 & 0.30 & 0.37 & 0.30 & 0.49 & 0.60 \\
\hline & \multirow{2}{*}{$\begin{array}{l}4 \text { Aralık } \\
2019\end{array}$} & güçlü ışın & 305 & -1.03 & 1.76 & 0.35 & 0.34 & 0.39 & 0.35 & 0.30 & 0.46 \\
\hline & & zayıf 1şın & 1107 & -1.91 & 2.59 & 0.28 & 0.27 & 0.35 & 0.29 & 0.37 & 0.40 \\
\hline \multirow{4}{*}{$\begin{array}{l}\text { Van Ferit } \\
\text { Melen } \\
\text { Havalimanı }\end{array}$} & \multirow{2}{*}{$\begin{array}{l}27 \text { Ekim } \\
2018\end{array}$} & güçlü işın & 1536 & -1.50 & 0.99 & -0.30 & -0.27 & 0.33 & 0.28 & 0.28 & 0.41 \\
\hline & & zayif 1şın & 451 & -0.99 & 0.81 & -0.32 & -0.35 & 0.34 & 0.35 & 0.24 & 0.40 \\
\hline & \multirow{2}{*}{$\begin{array}{l}20 \text { Mart } \\
2020\end{array}$} & güçlü işın & 1959 & -4.05 & 2.63 & -0.22 & -0.25 & 0.33 & 0.28 & 0.37 & 0.44 \\
\hline & & zayıf işın & 323 & -2.66 & 10.81 & -0.36 & -0.35 & 0.43 & 0.36 & 0.68 & 0.77 \\
\hline
\end{tabular}

verilerin kullanılması gerektiği sonucuna varılmıştır. Ancak güvenilirliği yüksek verilerin sayıca az olduğu durumlarda ise verilerde mutlaka bir kaba hata ayıklama işleminin uygulanması gerekliliği ortaya çıkmaktadır. Şekil 3'de sunulan ve iki havalimanına ait birer veriden alınan kesitler de bu sonucu doğrulamaktadır. Örneğin, 4 Aralık 2019 tarihli zayıf ışın verisinde orta ve yüksek güvenilirlik düzeyinde arakesit analizlerinde Erzurum havalimanında kaba hatalar olduğu görülmektedir (Şekil 3a,b). 20 Mart 2020 tarihli Van havalimanı çalışma alanına ait verinin farklı 1şın ölçütlerine göre kesit analizinde ise kaba hatalar daha net bir şekilde görülmektedir (Şekil $3 \mathrm{c}, \mathrm{d})$. Sonuçlarda bir diğer ilgi çekici husus ise iki çalışma bölgesi için ortalama mutlak hata ve ortanca mutlak hata değerlerinin birbirine çok yakın olmasıdır. Ancak mutlak değerler alınmadan hesaplanan ortalama ve ortanca hata değerleri incelendiğinde ise sonuçların Erzurum Havalimanı için pozitif, Van Ferit Melen Havalimanı için ise negatif işaretli olduğu görülmektedir. Bunun da LiDAR nokta bulutuna uygulanan jeoid ondülasyon değerleri ile ilişkili olacağ değerlendirilmekte olup bu bağlamda geoid-elipsoid yükseklik dönüşümlerinin belirli seviyede hata içerdiği anlaşılmaktadır. 


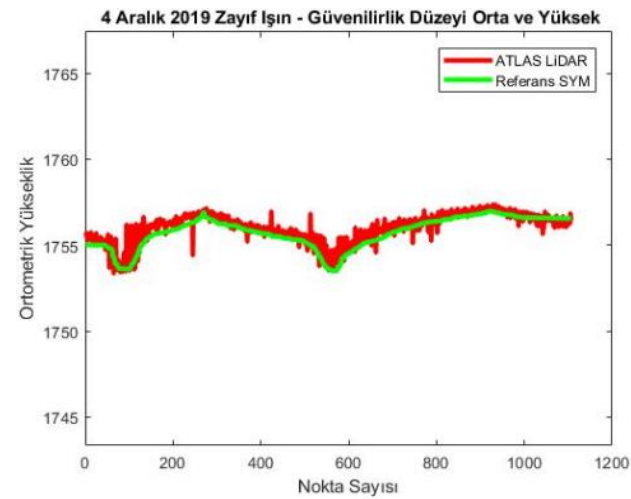

(a)

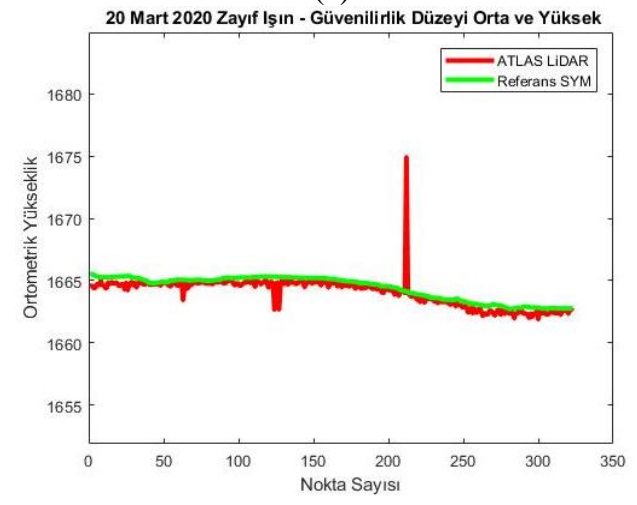

(c)

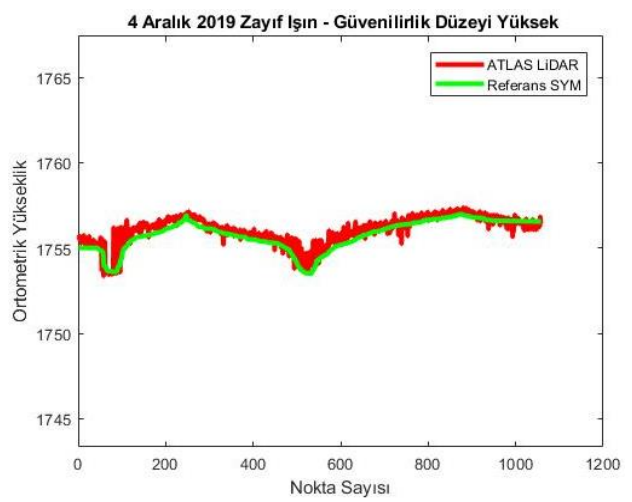

(b)

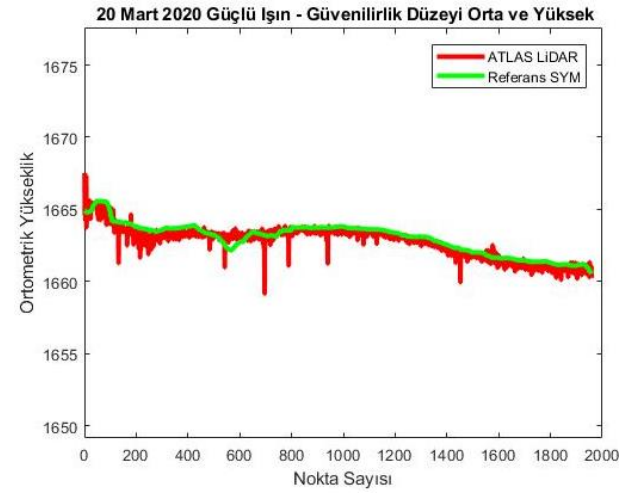

(d)

Şekil 3. (a, b) 4 Aralık 2019 tarihli Erzurum havalimanı çalışma alanına ait verinin farklı güvenilirlik ölçütlerine göre kesit analizi, (c, d) 20 Mart 2020 tarihli Van havalimanı çalışma alanına ait verinin farklı sinyal ölçütlerine göre kesit analizi

\section{Sonuçlar ve Öneriler}

Bu çalışmada, IceSat-2 uydusu nokta bulutu verileri kullanılarak kar kalınlığı belirleme hedefi doğrultusunda Erzurum ve Van Ferit Melen Havalimanları çalışma alanlarında doğruluk analizleri gerçekleştirilmiştir. ATL08 seviye $3 \mathrm{~A}$ veri ürünü hem arazi hem de bitki örtüsü (canopy) hakkında veri sağlamaktadır. Nokta bulutu verileri ile birlikte sağlanmış olan güvenilirlik düzeylerine göre filtrelemelerin yapılması önemli adımlardan biridir. Farklı tarihlerde alınan nokta bulutu verileri için iki farklı güvenilirlik düzeylerinde sonuçlar elde edilmiş ve analizleri yapılmıştır. Doğruluk analizlerini gerçekleştirmek adına referans SYM ile nokta bulutu verileri karşılaştırılmıştır. Sonuçlara göre güvenilirlik düzeyi yüksek olan veriler için ortalama karesel hatalar oldukça dar bir bantta değişmektedir $(0.32 \mathrm{~m}-0.49 \mathrm{~m})$. Tüm değerlendirmeler sonucunda IceSat-2 verilerinin güvenilirlik düzeyi yüksek verilerinin kaba hatalar içerebildiği ancak orta güvenilirlik düzeyi verilerinin daha fazla seviyede hatalar barındırdığı ortaya koyulmuştur. LiDAR nokta bulutuna uygulanan jeoid ondülasyon değerlerinin hassasiyetinin de istatistiksel sonuçları etkilediği düşünülmektedir.

Yapılan çalışmalar sırasında LiDAR uydularının bulutlu günlerde veri toplayamaması neticesinde bazı verilerde eksiklikler gözlenmiştir. Bununla beraber (i) IceSat-2 zamansal çözünürlüğün 91 gün olması nedeniyle istenilen tarihte veri toplanamaması neticesinde veri bulunmaması, (ii) 
jeoid ondülasyon dönüşümünün doğruluğu etkilemesi, (iii) farklı materyallerden ve yüzeylerden gelen yansımaların farklı olup sonuçları etkilemesi gibi sorunlarla karşılaşılmıştır. Gelecek çalışmalarda elde edilen LiDAR nokta bulutu verilerinden elde edilecek kar yüksekliği verileri metereoloji istasyonlarından elde edilen günlük kar yüksekliği verileri ile karşılaştırılacak ve IceSat-2 verilerinin kar yüksekliği belirleme potansiyeli değerlendirilecektir.

\section{Referanslar}

[1] Liston GE. Interrelationships among snow distribution, snowmelt, and snow cover depletion: Implications for atmospheric, hydrologic, and ecologic modeling. J Appl Meteorol 1999;38(10):1474-1487.

[2] Engeset R, Tveito OE, Alfnes E, Mengistu Z, Udnaaes HC, Isaksen K vd. Snow map system for Norway. XXIII Nordic Hydrological Conference 2004, 8-12 August 2004, Tallinn, Estonia, 2004;48(1):112-121.

[3] McClung DM. The elements of applied avalanche forecasting part I: The human issues. Nat Hazards 2002;26(2):111-129.

[4] Eckerstorfer M, Bühler Y, Frauenfelder R ve Malnes E. Remote sensing of snow avalanches: Recent advances, potential and limitations. Cold Reg Sci Technol 2016;121:126-140.

[5] Helfricht K, Schöber J, Seiser B, Fischer A, Stötter J, ve Kuhn M. Snow accumulation of a high alpine catchment derived from LiDAR measurements. Adv Geosci 2012;32:31-39.

[6] Baños IM, García AR, Alavedra JM, Figueras PO, Iglesias JP, Figueras PM vd. Assessment of airborne LiDAR for snowpack depth modeling. Bol la Soc Geol Mex 2011;63(1):95-107.

[7] Neuenschwander A ve Pitts K. The ATL08 land and vegetation product for the ICESat-2 Mission. Remote Sens Environ 2019;221- Kasim 2018:247-259.

[8] Neuenschwander AL ve Magruder LA. Canopy and terrain height retrievals with ICESat-2: A first look. Remote Sens 2019;11(14):1-13.

[9] Meteoroloji Genel Müdürlüğü. İl ve İlçeler Resmi İstatistikler. https://www.mgm.gov.tr/veridegerlendirme/il-ve-ilceler-istatistik.aspx

[10] ATLAS/ICESat-2 L3A Land and Vegetation Height, Version 3. https://nsidc.org/data/at108

[11] Neumann TA, Martino AJ, Markus T, Bae S, Bock MR, Brenner AC vd. The Ice, Cloud, and Land Elevation Satellite - 2 mission: A global geolocated photon product derived from the Advanced Topographic Laser Altimeter System. Remote Sens Environ 2019;2331: ISSN 0034-4257.

[12] Markus T, Neumann T, Martino A, Abdalati W, Brunt K, Csatho B vd. The Ice, Cloud, and land Elevation Satellite-2 (ICESat-2): Science requirements, concept, and implementation. Remote Sens Environ 2017;190:260-273.

[13] Neuenschwander A, Popescu S, Nelson R, Harding D, Pitts K, Robbins J vd. ICE, CLOUD, and Land Elevation Satellite (ICESat-2) $\mid$ Algorithm Theoretical Basis Document (ATBD) for Land Vegetation Along-track products (ATL08) Contributions; Temmuz 2018.

[14] Harita Genel Müdürlüğ̈̈. TG $19 \quad$ Duyuru $\quad$ Metni. https://www.harita.gov.tr/images/haberler/TG-19_Duyuru_Metni_14012020.pdf 